\title{
Uma investigação sobre a adoção da modularidade no projeto de novos produtos e na produção em uma montadora automotiva
}

\author{
Paulo Augusto Cauchick Miguel, PhD \\ Depto. de Engenharia de Produção, Escola Politécnica - USP \\ cauchick@usp.br
}

Olavo Viana Cabral Netto

olavo.netto@gmail.com

\section{Sandra Naomi Marioka}

sandra.morioka@poli.usp.br

As mudanças constantes no mercado exigem das empresas constante evolução no desenvolvimento de novos produtos. Uma das práticas empregadas é a adoção do projeto modular para desenvolver novos produtos e/ou o uso da modularidade na produção. Nesse sentido, o objetivo deste trabalho é fazer uma análise dessas práticas em uma montadora de veículos. São investigadas a compreensão do conceito de modularidade pelas áreas funcionais de engenharia do produto e produção e a identificação de práticas adotadas pela empresa. Quanto aos métodos utilizados, esses consideram primeiramente uma revisão da literatura, seguida de uma pesquisa de campo utilizando como fontes de evidência na coleta de dados entrevistas semiestruturadas e análise documental. A partir dos resultados, pode-se concluir que os conceitos associados à modularidade são diferenciados entre as áreas de desenvolvimento de novos produtos e produção, principalmente no que se refere à compreensão do que se constitui um módulo.

Palavras-chave: modularidade, indústria automotiva, desenvolvimento de produto

Constant changes in the market have demanded constant evolution in the development of new products. One of the current practices is the adoption of modular design to develop new products and the use of modularity in production. In that sense, the objective of this paper is to analyse the adoption of modularity in design and production in a vehicle assembler. It is also investigated the understanding of modular concept for the functional areas of product engineering and production, and the identification of what is adopted by the company. Regarding the research methods firstly consider a bibliography review followed by a field research using as source of evidence data collected through semistructured interviews and document analysis. From the results, it is possible to conclude that the concepts associated with modularity are distinct in the areas of product development and production, mainly those related with what constitutes a module.

Keywords: modularity, automotive industry, product development

\section{Introdução}

Nas últimas décadas, as empresas do setor automotivo vêm sendo impulsionadas a adaptarem-se à dinâmica global de competitividade a satisfazer as necessidades de clientes cada vez mais exigentes. $\mathrm{O}$ desenvolvimento de novos produtos tornou-se, assim, uma das atividades desafiadoras na gestão organizacional. Pressionados por resultados mais eficazes nos produtos lançados no mercado e por prazos de lançamento mais reduzidos, as equipes de engenharia de produto enfrentam diversos desafios no desenvolvimento de novos produtos. Estes desafios fazem com que as empresas busquem novas soluções organizacionais para o projeto do produto e sua produção. Uma dessas abordagens é a adoção da modularidade, introduzida nos últimos 10 anos na indústria automobilística tanto no Brasil quanto no exterior.

A modularidade é um abordagem baseada na divisão de um produto (ou produção) em subsistemas independentes, 
geralmente de menor porte, que tem como principais objetivos (BALDWIN; CLARK, 2004): facilitar o gerenciamento de produtos e processos de produção e organizacionais, possibilitar a realização de atividades de desenvolvimento de novos produtos em paralelo, e adaptar a produção às incertezas futuras. Assim, permite a produção de produtos diversificados por meio da combinação de subsistemas (LEE et al., 2001; YIGIT et al., 2002), além de possibilitar ganhos com a alteração da configuração dos processos produtivos.

O objetivo deste trabalho é analisar a adoção do projeto modular e da modularidade na produção em uma montadora de veículos. Mais especificamente, as variáveis investigadas correspondem à compreensão do conceito de modularidade por estas áreas (produto e produção) e identificação de práticas adotadas pela empresa, considerando-se a relação entre o desenvolvimento de novos produtos modulares e a modularidade na produção. Para cumprir estes objetivos, foi selecionado um objeto de análise (montadora automotiva) que foi investigado por meio da abordagem de estudo de caso, uma vez que o fenômeno (adoção da modularidade por esta empresa) e seu contexto (no desenvolvimento de novos produtos e na produção) são, particularmente, relevantes. Nesse contexto, descreve-se na sequência, o referencial teórico com base nos conceitos sobre a modularidade e seus tipos principais e, em seguida, detalhes sobre os métodos e técnicas de pesquisa adotadas na investigação. A seguir, os resultados são apresentados, seguidos por sua discussão e conclusões principais.

\section{Referencial teórico}

A modularidade é baseada na divisão de um produto em subsistemas que são projetados de modo independente mas que são interdependentes na sua operação (BALDWIN; CLARK, 1997). Um sistema modular tem por objetivos (BALDWIN; CLARK, 1997; 2004): facilitar o gerenciamento de produtos e processos por meio da divisão em módulos; possibilitar a realização de atividades em paralelo, já que os módulos podem ser manufaturados simultaneamente; e adaptar a produção às incertezas de demanda futura, pois o produto final poder ser modificado pela adaptação de qualquer dos módulos, o que pode exigir menor consumo de recursos.

Para ajudar a compreender a modularidade, é necessário explicitar que a arquitetura de um produto é a forma com que os elementos funcionais (relacionados à operação desse produto) são designados aos elementos físicos (subsistemas e componentes). $\mathrm{O}$ conceito de modularidade influencia e transforma a lógica de estruturação desta arquitetura, contrapondo a arquitetura integral à modular. Por um lado, na arquitetura integral os elementos funcionais e suas interações estão estritamente entrelaçados, isto é, existe grande interdependência do ponto de vista de arquitetura do produto entre esses componentes. Sendo assim, caso um componente específico seja substituído por qualquer razão, é necessário que haja uma reformulação integral do produto, redefinindo o entrelaçamento dos elementos funcionais e físicos, o que significa um projeto mais complexo para o novo produto. Por outro lado, ao se analisar a arquitetura modular, verifica-se que um conjunto de elementos físicos é responsável por poucos elementos funcionais e, neste sentido, a modularidade pode ser compreendida como sendo uma estratégia de engenharia que procura considerar o produto final como sendo a união de subsistemas mais simplificados (BALDWIN; CLARK, 1997). Para viabilizar isso, surge a necessidade do detalhamento das características funcionais do produto, de modo a possibilitar a delimitação do que será considerado um módulo e como serão definidos os elementos de interface entre eles. Assim, cada módulo pode ser projetado independentemente, mas sempre atentando à interdependência entre os próprios módulos, para que o produto final seja eficaz e ao mesmo tempo alcance o menor custo possível.

A vantagem imediata deste tipo de arquitetura modular está no fato de que uma eventual mudança no projeto de um módulo independe dos outros módulos (ULRICH; EPPINGER, 1995), ou seja, caso seja necessária a alteração de uma determinada característica que foi alocada a um determinado módulo, a revisão e a reformulação do projeto integral do produto final, em geral, não serão necessários, bastando apenas que sejam mantidas as premissas iniciais da concepção do módulo. Essa flexibilidade facilita a atualização, manutenção, reparação e desuso de um determinado produto (O'GRADY, 1999) e só é possível devido à padronização das interfaces que interligam os módulos (BALDWIN; CLARK, 2000).

A modularidade pode ser classificada em três categorias (BALDWIN; CLARK, 2000): de projeto, de processo ou de uso. Em função do escopo do presente trabalho, são detalhadas a modularidade de projeto e a de processo (produção).

A modularidade de projeto é também conhecida como modularidade de produto, pois é a partir dela que se definem os módulos de cada produto e os componentes que fazem parte de cada um deles. É nesse momento que a função de cada subsistema é especificada, assim como são pré-definidos os elementos de interface. Já a modularidade de processo, que também é conhecida como modularidade de produção, está relacionada ao processo produtivo propriamente dito, simplificando os processos de produção, os quais podem ser subdivididos em etapas definidas conforme os módulos. Como reflexo disso, os fornecedores podem ser responsabilizados por alguns processos de submontagem e testes (CAMUFFO, 2000). Por fim, a modularidade de uso é aquela que possibilita a adaptação do produto final ao cliente, pelo rearranjo dos 
módulos (BALDWIN; CLARK, 2000). Os dois primeiros tipos de modularidade serão detalhados mais adiante.

A estratégia modular no desenvolvimento de produtos pode ser aplicada a diversos setores econômicos, tais como a indústria de eletroeletrônicos, de telecomunicações, a aeronáutica, a indústria naval, entre outras (ANDO, 2004). $\mathrm{Na}$ indústria automobilística brasileira e mundial, pode ser verificada uma grande aplicação da estratégia modular. Esse fato leva a crer que é importante e necessário um estudo mais aprofundado de suas principais características e consequências, como destacado a seguir.

\subsection{Tipos de modularidade}

Como destacado anteriormente, a modularidade de projeto ou de produto, é aquela em que se define os componentes de cada um dos módulos que comporão cada produto no mix de produtos da empresa. Esse tipo de modularidade possibilita a interferência dos fornecedores dos módulos no processo de desenvolvimento. Assim, esses fornecedores podem se tornar cada vez mais especialistas em um determinado módulo o que, em teoria, deveria impulsionar o avanço tecnológico pontual de cada módulo. Porém, na indústria automotiva, a modularidade no projeto de produto é a menos explorada (BALDWIN; CLARK, 1997), apesar de estar em constante crescimento (PANDREMENOS et al., 2009). Em geral, no ocidente a tendência das montadoras é centrar esforços na modularidade de produção, enquanto a indústria automotiva japonesa é mais inclinada para a adoção da modularidade em projeto (PANDREMENOS et al., 2009). Vale destacar que existem dois tipos de informações que guiam um projeto: as visíveis (ou normas) e as não visíveis. As informações normativas são praticamente imutáveis e estabelecidas nas fases iniciais do projeto pelas montadoras, responsáveis pela integração do produto final (GRAZIADIO, 2004). Esse tipo de informação determina em cada módulo a sua própria concepção, as suas interações, as suas funções (como unidade e como sistema) e seus elementos físicos, além de seus ajustes e conexões entre os demais módulos. Em contrapartida, as informações não visíveis são aquelas determinadas pelo projetista do módulo e suas eventuais modificações dispensam notificações aos arquitetos do sistema do produto como um todo, devido à independência do projeto dos módulos (GRAZIADIO, 2004). Nesse contexto, a modularidade de projeto de produto pode trazer benefícios tanto às montadoras como aos seus fornecedores. $\mathrm{Na}$ maioria dos casos, essa categoria de modularidade está geralmente associada à modularidade de produção, já que esta depende diretamente da forma com que o produto foi desenvolvido e projetado. Sendo assim, os parágrafos que seguem exploram este segundo tipo de modularidade.
A modularidade de produção está relacionada ao processo produtivo propriamente dito, simplificando a manufatura e montagem. Esse tipo de modularidade é mais comumente aplicado na indústria automotiva, porque permite às montadoras aumentar a produtividade e reduzir os custos de produção (BALDWIN; CLARK, 1997). A estrutura modular do processo de produção visa à simplificação da linha de montagem por meio da implementação de pré-montagens e pré-testes funcionais para os módulos. As principais vantagens deste tipo de modularidade são: diminuição da complexidade da linha principal de montagem, maior eficácia no controle da qualidade, melhoria da ergonomia dos equipamentos e dos postos de trabalho (HELPER et al., 1999) e redução dos estoques de produto acabado. Um caso a ser citado é o da linha de montagem na fábrica de caminhões e ônibus da Volkswagen, localizada em Resende, no Estado do Rio de Janeiro, inaugurada em 1996 (ARBIX; ZILBOVICIUS, 1997; RAMALHO; SANTANA, 2002). Outro aspecto relevante na modularidade de produção é o grau de flexibilidade nas variações ( $m i x$ ) de produto, que pode ser alcançado através da implementação de diferentes tipos de módulos pré-montados, mantendo-se os custos variáveis (STARR, 1965). Isso ocorre porque o acoplamento de diferentes módulos pode originar um produto diferente que pode ser adequado às necessidades específicas de cada um dos clientes. Além disso, diferentes módulos que atendem vários produtos na linha de montagem permitem minimizar o tempo entre o momento em que o pedido é feito e o momento em que o produto é finalizado, possibilitando a adaptação da linha de produção às eventuais flutuações do mercado.

\subsection{Desenvolvimento do projeto modular}

A adoção da arquitetura modular para o desenvolvimento de novos produtos não segue um fluxo linear de atividades, diferentemente da arquitetura convencional (O'GRADY, 1999). No desenvolvimento da arquitetura modular, podem-se identificar uma sequência de atividades que ocorrem em paralelo. São desenvolvidas as etapas de desenvolvimento conceitual do produto, dos módulos, e da montagem do produto, cada uma com suas atividades específicas. A etapa de projeto conceitual inclui as três primeiras atividades de um processo convencional de desenvolvimento de novos produtos, isto é, identificação das exigências dos clientes, definição das especificações gerais do projeto do produto, e macro planejamento do processo de produção. Esta etapa de projeto geral representa o principal input no desenvolvimento de novos produtos, pois a partir dela todas as variações de produto já são definidas. Sendo assim, pode-se prosseguir à etapa de desenvolvimento e projeto detalhado dos módulos, os quais definem as características e os atributos individuais de cada um. Feito isso, a montagem do produto fica 
restrita à identificação das exigências individuais de cada cliente, para que seja feita a seleção dos módulos mais adequados e a montagem customizada do produto final.

Diferentemente da arquitetura convencional, a mudança em alguma parte do projeto modular, pode ser realizada sem a necessidade de reformulação de todo o projeto do produto (O'GRADY, 1999). Se a empresa integradora optar por utilizar módulos pré-existentes, o desenvolvimento de novos módulos faz-se necessário. Isso faz com que a empresa alcance vantagem competitiva à medida que ganha tempo por meio da redução do lead time de desenvolvimento (ARBIX, ZILBOVICIUS, 1997; O'GRADY, 1999).

É importante também ressaltar que a modularidade permite obter um sistema de controle de produção mais simplificado, uma vez que pode ser mais aberto, flexível e descentralizado, se comparado àquele presente em uma planta convencional (ARBIX, ZILBOVICIUS, 1997; O'GRADY, 1999). Isso decorre em função do modo como os módulos podem ser operados independentemente entre si, em que o integrador executa apenas o controle mais geral do processo. Além disso, a relação entre o número de módulos e o número de componentes de um determinado produto é pequena, simplificando ainda mais o controle pelo integrador (ARBIX; ZILBOVICIUS, 1997; BALDWIN; CLARK, 1997; O'GRADY, 1999).

Um dos potenciais inconvenientes da modularidade é o consumo excessivo de tempo, recursos e esforços na fase inicial do projeto dos módulos, isto é, na fase de concepção do projeto geral (O'GRADY, 1999). Além disso, o produto modular pode ter índices de desempenho ligeiramente menor que aquele desenvolvido especialmente para uma determinada tarefa, porque há possibilidade de utilização de módulos redundantes, ou seja, de módulos cujas funções podem estar sobrepostas. Ainda segundo o autor, para produtos de baixa escala que são muito especializados, a modularidade pode não ser uma estratégia adequada para o desenvolvimento de novos produtos, já que o aproveitamento do mesmo módulo em diversas situaç̃̃es, uma das principais vantagens do conceito modular, é reduzido. Cabe destacar também que os módulos podem também influenciar a qualidade e confiabilidade do produto.

\subsection{Montadoras e fornecedores e sua relação com a modularidade}

Na modularidade de produto e de produção, a montadora tem como principal função o gerenciamento e a integração dos módulos, definindo as funções de cada um dos módulos como unidade independente e como parte integrante do sistema produto final (BALDWIN; CLARK, 1997). Essas funções devem ser exercidas tendo sempre em vista o compromisso em atender as necessidades e expectativas dos clientes, buscando reduzir (ou eliminar) os atrasos no tempo de entrega, além de menor custo e de maior qualidade (O'GRADY, 1999). Em contra partida, os fornecedores são responsabilizados pelo desenvolvimento e manufatura do módulo propriamente dito (BALDWIN; CLARK, 1997).

A produção de um módulo completo é mais complexa e necessita de um conhecimento tecnológico diferenciado daquele utilizado na manufatura de um componente individual do módulo. Por isso, é necessário que os fornecedores de módulos sejam capazes de lidar com isso (BALDWIN; CLARK, 1997). Porém, somente obter tecnologia adequada não é suficiente para um bom desempenho de um fornecedor, pois ele deve ter também a capacidade de integrar, gerenciar e criar alianças estratégicas com seus subfornecedores para manter seu fluxo de produção com qualidade (ANDO, 2004). Além disso, os fornecedores devem ter uma razoável capacidade financeira, para poder assumir parte das despesas associadas à engenharia e ao ferramental necessário (ALLER, 1999), acompanhar as montadoras em cada país (follow sourcing), e garantir os investimentos necessários para as inovações nos produtos e nos processos além de se adaptar às flutuações do mercado (DIAS, 1998). Como resultado, estes fornecedores acabaram tomando a maior parcela do mercado por satisfazer mais adequadamente essas necessidades das montadoras (ANDO, 2004).

A localização dos fornecedores nas proximidades das montadoras tem como principais vantagens a agilidade na assistência técnica dos fornecedores na linha de montagem final do integrador e a capacidade de adaptação às variações da demanda, devido à flexibilidade de sua reprogramação (SALERNO et al., 1998). Isso ocorre em virtude do menor tempo de transporte entre os fornecedores e as montadoras e, portanto, menor tempo de entrega, além da maior facilidade para a resolução de problemas.

O serviço dos fornecedores de módulos dos veículos de plataforma mundial pode ser classificado como global sourcing ou follow sourcing (FRESSENET; LUNG, 2000). Na estratégia de global sourcing, os componentes são fornecidos numa situação em que qualidade, custo e prazo de entrega são obtidos da melhor forma possível (FRESSENET; LUNG, 2000), considerando também as barreiras comerciais e fluxo de informações necessárias entre os países de origem e de destino dos componentes (ANDO, 2004). Uma característica importante dessa situação é a exploração dos recursos locais dos fornecedores, tais como tecnologia, matéria-prima, mão de obra, entre outros (ANDO, 2004). A situação mais comum em que se aplica o global sourcing é nos componentes de alta tecnologia ou então nos componentes de baixa tecnologia cujo custo de produção seja baixo o suficiente para compensar um estoque elevado (DIAS, 1998). Em contra partida, na estratégia de follow sourcing o fornecedor acompanha 
a montadora naquelas regiões ou países em que a montadora está instalada. É possível diminuir o tempo de fabricação, custo e preço dos componentes ou módulos por se tratar de uma tecnologia já desenvolvida no país de origem. Existe ainda a possibilidade da montadora não absorver suficientemente o fluxo produtivo dos fornecedores, as quais acabam procurando contrato com outras montadoras e associações com fornecedores locais com joint ventures ou aquisições (DIAS, 1998; HAMPHREY et al., 2000). De acordo com Humphrey et al. (2000), o Brasil tem adotado preferencialmente o follow sourcing nas suas estratégias de produção.

As montadoras no setor automotivo têm a tendência de estabelecer relacionamento com os fornecedores em contratos de longo prazo, isto é, pelo tempo de vida do próprio veículo (ANDO, 2004). Para manter a competitividade, as montadoras seguem a cláusula de "manutenção de competitividade" que permite às montadoras fazerem cotações com outros fornecedores, comparando preços e condições, que podem acabar culminando na troca de fornecedores (SALERNO et al., 2002). Essa tarefa de substituição não é simples devido à restrita gama de opções dentro do oligopólio nesse setor de fornecimento de componentes, gerado pela dificuldade de manutenção de uma empresa fornecedora (ANDO, 2004).

É interessante notar que a relação entre montadora e fornecedor acaba ficando cada vez mais reforçada, devido aos contratos de longo prazo. Assim, ocorre um aumento da dependência entre as partes, reforçado também pelo intenso fluxo informacional entre eles. Neste novo contexto, o fornecedor assume uma nova posição na cadeia de suprimentos. $\mathrm{O}$ fornecedor deixa de ser apenas uma empresa de auxílio externo e passa a agregar uma parcela importante do valor ao produto final. Esse fornecedor diferenciado participa ativamente no desenvolvimento da tecnologia, dos processos de produção, da logística, do desenho e da integração da cadeia de subfornecedores (VAN HOEK,WEKWN, 1998).

A modularidade interfere na participação dos fornecedores em três frentes principais: produto, produção e sistema de suprimentos (GRAZIADIO, 2004). Sob o ponto de vista do produto, os fornecedores podem se envolver não só na inovação de produtos como no desenvolvimento dos módulos, através da troca de informações e da divisão de custos com as montadoras; na produção, os fornecedores se preocupam com a infraestrutura da pré-montagem dos conjuntos, o controle de qualidade e o bom funcionamento de uma determinada peça ou conjunto de peças em seus respectivos módulos. Tudo isso também é auxiliado pelo fluxo de informações entre fornecedores e montadoras (GRAZIADIO, 2004). Já no sistema de suprimentos, é necessário escolher os subfornecedores de peças avulsas, implementar uma logística adequada de ciclos e sistemas de entregas, tamanho dos lotes e dos estoques, além de manter uma comunicação eficaz entre as empresas para certificar o andamento adequado. É válido ressaltar que o grau de participação de cada fornecedor no desenvolvimento do produto final depende da escolha da montadora e varia com as partes do veículo (GRAZIADIO, 2004).

A escolha da empresa que se responsabilizará pelo fornecimento das peças avulsas ou do módulo inteiro é de extrema importância para a montadora, já que esta deixa de ser a única a agregar valor ao produto final. A especialização dos fornecedores em um determinado módulo tende a um desenvolvimento tecnológico importante para o setor, mas as montadoras são cautelosas em ainda manter boa parte do projeto final em informações normativas e padronizadas de modo a conservar os principais dados estratégicos de interface entre os módulos (BALDWIN; CLARK, 1997).

A partir desse referencial teórico, alguns pontos importantes emergem na adoção da estratégia modular, seja esta voltada para o projeto do produto ou para a sua produção. Observa-se, por exemplo, a possibilidade da existência de uma relação estreita entre estes dois tipos de modularidade, uma vez que as decisões tomadas podem afetá-los mutuamente. Por exemplo, as decisões de um projeto modular para um novo produto pode implicar limitações (ou dificuldades) para a montagem e viceversa, isto é, o modo como a montagem é organizada pode limitar a adoção da arquitetura modular pois o investimento pode ser alto com um período de retorno muito longo. Assim, torna-se relevante investigar a adoção desses tipos de modularidade e suas respectivas práticas, de modo a estabelecer uma base para investigar a relação entre eles (produto e produção). A partir dessa constatação, em nível teórico, realiza-se, então, uma investigação empírica, cujo trabalho de campo é detalhado a seguir, bem como seus resultados.

\section{Métodos e procedimentos adotados na presente investigação}

Na engenharia de produção é comum a utilização de métodos racionalistas de pesquisas, sobretudo análises estatísticas (VOSS et al., 2002), para a análise de situações reais. A principal característica deste tipo de método de pesquisa é a independência do fenômeno investigado do contexto em que se insere. Este aspecto, de certa forma, contrapõe-se ao fato da engenharia de produção ser reconhecida como uma área aplicada em que o contexto do fenômeno investigado é relevante. Por este motivo, algumas abordagens alternativas têm sido exploradas nos estudos de gestão organizacional, tanto em setores industriais quanto de serviços (FILIPPINI, 1997). Uma das abordagens metodológicas de pesquisa que mais tem se destacado é o estudo de caso (MIGUEL, 2007). É uma 
abordagem empírica cujo objetivo é investigar um fenômeno contemporâneo em um contexto real por meio de múltiplas fontes de evidências (MIGUEL, 2007). No presente trabalho, a abordagem de estudo de caso foi escolhida, pois, além do tema ser contemporâneo (modularidade), o contexto (sua aplicação em dado setor industrial, no caso automotivo, no projeto do produto e na produção) é importante. Mais ainda, os dados de pesquisa são de natureza qualitativa-descritiva, sendo, portanto, compatíveis com este tipo de abordagem metodológica de pesquisa. A condução do caso foi subdividida em três etapas, iniciando-se pela 1. revisão bibliográfica e construção do referencial teórico para sustentar a etapa de pesquisa em campo, 2. seleção do objeto de estudo e desenvolvimento do instrumento de coleta de dados (roteiro de entrevistas) e 3. a condução propriamente dita e análise dos resultados, destacados a seguir.

Como destacado na introdução, o objetivo geral da presente investigação é o de analisar a adoção do projeto modular e da modularidade na produção. A questão de pesquisa estaria relacionada à "como a montadora utiliza a modularidade e suas práticas?’. As variáveis investigadas envolvem a compreensão do conceito de modularidade pelas áreas funcionais (de produto e produção), bem como a identificação de práticas adotadas pela empresa nesse sentido. Em última instância, em nível de exploração, também considera uma análise da relação entre o desenvolvimento de novos produtos modulares e a modularidade na produção. Assim, a coleta dos dados (descrita a seguir) foi conduzida considerando o desdobramento em questões associadas a estas variáveis de pesquisa. Em um primeiro momento, é feita uma análise de modo separado (modularidade no desenvolvimento de novos produtos e modularidade na produção, estas consideradas como as duas as unidades de análise). Posteriormente, é realizada uma tentativa inicial para estabelecer uma relação causal (preliminar) entre as duas unidades de análise. Cabe ainda destacar que visitas estruturadas ao centro de desenvolvimento de produtos da empresa e à fábrica possibilitaram a observação de variáveis e práticas in loco, contribuindo também como uma importante fonte de evidência.

Além das visitas estruturadas citadas anteriormente, os dados foram predominantemente coletados por meio de três entrevistas semiestruturadas, conduzidas em duas visitas à empresa. As entrevistas foram realizadas com quatro profissionais que atuam no desenvolvimento de novos produtos e na produção, em diferentes níveis hierárquicos (engenheiros sêniores e gerentes). As entrevistas foram gravadas e posteriormente transcritas, possibilitando uma análise de conteúdo com base em práticas de analise qualitativa de dados, com base em Miles e Huberman (1994). A unidade de análise foi selecionada por ter participado de projetos de pesquisa anteriores conduzidos pelo grupo, tendo sido identificado $a$ priori a adoção da modularidade nas práticas de projeto modular. Para a escolha do objeto de análise, foi também considerado a possibilidade de acesso aos dados necessários para compor o trabalho de pesquisa, incluindo a disponibilização de documentos internos da organização, utilizados para a análise documental. A possibilidade de fontes de evidências diversificadas permitiu o uso de triangulação dos dados visando maior confiabilidade na análise dos resultados da pesquisa, descritos a seguir.

\section{Resultados}

A partir da seleção do objeto de análise (empresa) e das unidades de análise (projeto de produtos ou produção), inicialmente são fornecidas algumas indicações sobre o contexto do trabalho. Após este contexto, a descrição dos principais dados, coletadas em campo, é feita, seguida por uma análise preliminar organizada segundo o tipo de modularidade, i.e. projeto ou produção.

\subsection{Contexto da investigação}

O objeto de análise deste trabalho é uma montadora multinacional de grande porte que atua no setor automotivo com diversos produtos, desde veículos de carga até veículos de passeio. Mais especificamente, foi estudada uma de suas plantas que se dedica às áreas de negócios de caminhões, chassis e plataformas para ônibus, além de motores e eixos. Nesta fase do projeto de pesquisa, a plataforma para ônibus foi investigada.

Em um passado recente, as previsões da empresa indicavam que o mercado de ônibus demandaria cada vez mais diversificação na composição das famílias de produtos, com variações de potência de motor, trem de força, suspensão dianteira e traseira, quantidade de eixos, posição do motorista e outros fatores que afetam significativamente a estrutura de um chassis. Portanto, haveria uma necessidade de serem projetadas muitas variantes de chassis para suprir tais diferentes combinações das variações, além de diferenças do porte e geometria estrutural dos chassis e de seus componentes. Considerando o conceito tradicional de desenvolvimento de um novo produto (desenvolver soluções específicas para cada variante), esta situação tornar-se-ia impraticável, pois os custos de desenvolvimento seriam elevados e a produção seria muito específica para cada variante, sem uma escala que justificasse tais investimentos. Assim, a estratégia utilizada pela empresa foi a adoção do conceito modular no desenvolvimento de produto para atender a flexibilização do mix de produtos, a partir do final da década de 90, mas mais intensivamente desde 2007. A modularidade viria então como uma solução para flexibilizar as famílias de produtos, em que os módulos com interfaces padronizadas poderiam ser alocados nas diversas variantes. Dentre os benefícios da modularidade observados na coleta dos dados, pode-se citar a redução da complexidade do produto, 
diminuição de recursos para desenvolvimento, aumento da variedade de produtos e da flexibilidade da produção.

Na empresa estudada, o conceito de desenvolvimento do novo produto inicia com a definição das dimensões principais do veículo e do layout interno (disposição de assentos e dos compartimentos de carga), além dos cálculos iniciais de resistência dos eixos, com o objetivo de criar um ônibus que possa carregar a maior quantidade de lugares, respeitando as restrições legais de carga por eixo em cada país (ou seja, o produto deve atender as especificações técnicas e as restrições legais para cada mercado). Para os ônibus metropolitanos, o estudo do layout interno é orientado para encontrar a melhor disposição dos assentos de modo a respeitar os limites legais e o conforto dos passageiros. Além disso, o conforto e a estabilidade do veículo são as principais preocupações durante a fase do conceito. É importante destacar que, em virtude da estratégia da corporação (matriz), o centro de desenvolvimento no Brasil é responsável pelo projeto de todos os chassis comercializados por ela, o que implica um aumento no número de projetos desenvolvidos pela área de engenharia do produto, por necessitar atender a diversos mercados. Essa quantidade de projetos também é devido às diferenças legais entre cada país, uma vez que a empresa exporta para vários países, principalmente da América Latina. Desse modo, surge uma oportunidade para a adoção do projeto modular, descrito a seguir, de modo a minimizar esta quantidade de variantes.

\subsection{Desenvolvimento do projeto modular}

Foi feita uma divisão do projeto do ônibus em cinco módulos (ilustrados na Figura 1): M1 - posto do motorista; M2 - eixo dianteiro; M3 - módulo de transporte; M4 - eixo traseiro e $3^{\circ}$ eixo (quando for o caso); e M5 trem de força.

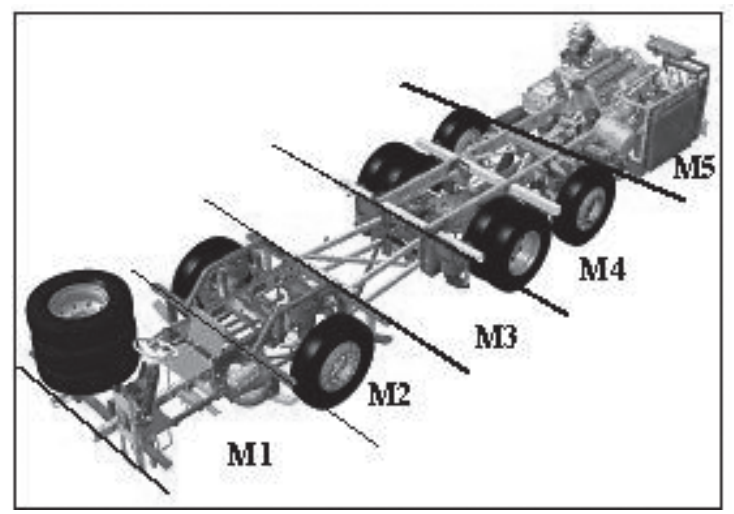

Figura 1 - Divisão por Módulos (Fonte: empresa estudada).

O projeto do veículo compreende diversos subsistemas, tais como: suspensão, freios, transmissão, entre outros. $\mathrm{O}$ chassis agrega todos estes subsistemas e a estrutura principal é denominada de "quadro". Como os esforços no desenvolvimento desses subsistemas demandam investi- mentos, a equipe de desenvolvimento procura utilizar os módulos já desenvolvidos, considerando a tendência de comercialização mundial do produto. A equipe de projeto também esforça-se em respeitar as capacidades e competências de cada um dos principais fornecedores locais na seleção desses módulos. Com o conceito do produto definido, o objetivo passa a ser desenhar um quadro de chassis que demonstre confiabilidade em um período curto de tempo. Como o quadro do chassis sofre grande influência dos subsistemas, seu desenvolvimento ocorre simultaneamente com o desenvolvimento dos módulos. Para isso, utilizam-se ferramentas de tecnologia da informação para criar um modelo 3D da estrutura a ser usada durante a análise estrutural, o que, consequentemente, fornecerá uma noção mais precisa sobre o comportamento do produto durante seu funcionamento.

O modelo é então enviado à etapa de análise, na qual serão verificados os pontos fracos da estrutura, através de simulação por elementos finitos. Durante o processo de simulação, todos os inputs são fornecidos pela fase de conceito e atualizados quando necessários. A estrutura do corpo é modelada de modo a testar a capacidade do carro, supondo o carregamento máximo permitido do eixo, a fim cumprir todos os requisitos legais, avaliar as necessidades dos mercados e dar segurança ao veículo durante a operação. Neste momento, o fluxo de informações é estabelecido entre a análise e o conceito para otimizar o tempo de resposta entre a identificação de um ponto fraco e o ajuste de projeto.

Segundo as políticas da corporação acerca de desenvolvimento de novos produtos, o projeto utiliza quatro protótipos ao longo do desenvolvimento. O primeiro protótipo (P1) tem por objetivo uma verificação macro do posicionamento e da montagem dos componentes. O segundo (P2) utiliza as posições pré-definidas dos componentes, o que possibilita um quadro bastante fiel do produto final para ser verificado na fase de análise por meio de diversos testes. $\mathrm{O}$ terceiro protótipo $(\mathrm{P} 3)$ apresenta o design final do chassis, aprovado pela fase de análise, sendo os módulos aprovados pelos testes. Por fim, o quarto protótipo (P4) é construído como forma de verificar as restrições de documentação do projeto e de produção, completando assim o ciclo de projeto para validar o início da produção.

De modo a avaliar a estrutura principal e o comportamento dos seus componentes funcionais no $\mathrm{P} 2$, o conceito do produto é submetido a testes de desempenho e, em paralelo, o modelo de elementos finitos (FEA - Finite Element Analysis; para este conceito ver Moaveni, 2000) é preparado para os testes de durabilidade. Além disso, simultaneamente, realizam-se testes para verificação dos ajustes entre os projetos da "unidade integradora" (módulo base) e das "unidades fornecedoras" (os outros 


\section{Produto \& Produção, vol. 10, n. 3, p. 07 - 18, out. 2009}

módulos), o que auxilia e antecipa a identificação dos problemas de montagem na simulação pré-fabricação final. Assim que o conjunto de testes é concluído e as alterações efetuadas, o modelo de FEA pode então ser atualizado para uma nova bateria de verificações. Podese considerar que existem 4 momentos principais de avaliação no projeto: 1) análise de frequência e durabilidade (P2); 2) análise estática e dinâmica, considerando os testes funcionais (P2); 3) análise estática e dinâmica, considerando os testes de produção e montagem (P3); 4) análises finais para validação do projeto.

Foi identificado nas entrevistas realizadas que o conceito de módulo para a engenharia de produto pode estar relacionado à função de determinado componente no produto final. Assim, se um componente desempenha a mesma função em diferentes partes do veículo ou se ele faz parte de um sistema mais amplo que desempenha uma única função, este componente é tratado como um módulo. Esse conceito de módulo, na forma como é entendido pela engenharia de produto, facilita o processo de desenvolvimento de um novo produto, principalmente considerando o modo que foi desenhado na proposição dos quatro protótipos. As interfaces, por sua vez, são definidas com base nos limites físicos dos módulos, ou seja, nas suas formas de conexão com os outros módulos e com o módulo base (o módulo base é denominado de quadro).

Com relação a aspectos de desempenho e qualidade, a adoção do conceito modular neste processo de desenvolvimento e testes permite a avaliação do desempenho de cada módulo individualmente em relação à sua eficácia no produto final. Assim, a avaliação e o diagnóstico das eventuais falhas do produto final podem ser realizadas mais rapidamente, o que confere maior agilidade ao processo e, portanto, tende a diminuir o time-to-market. Este conceito de estrutura modular em cinco módulos (Figura 1) é a principal prática na adoção da modularidade no projeto do produto da empresa. No entanto, a equipe de desenvolvimento foca mais no projeto propriamente dito e não na produção. Com isso, existe um risco (recorrente) de que um módulo novo seja desenvolvido sem antes verificar-se a possibilidade de adaptar o módulo existente (que, por sua vez, já tem o seu ferramental de produção). Observa-se, então, a primeira discrepância entre a definição da modularidade no projeto e, a posteriori, na produção.

\subsection{Modularidade na produção}

O conceito geral de montagem dos veículos pode ser caracterizado pela adoção de direcionadores importantes, tais como flexibilidade da produção, alto rendimento (output) e controle da qualidade. Dentre os principais desdobramentos deste conceito nas linhas de montagem da empresa destacam-se as montagens com kits e sistemas modulares e supermercados adjacentes aos postos de trabalho.
A estruturação do processo de montagem dos chassis, da forma como é desenvolvida atualmente, é dividida em duas etapas: montagem bruta e montagem final. A montagem bruta representa o processo básico de produção do veículo, no qual todos os carros (uma denominação interna genérica para qualquer tipo de veículo) são obrigados a passar. Sua finalidade é de realizar a montagem do módulo base, sendo a linha estruturada como um sistema de produção puxado, facilitado pelo layout da planta e pelo armazenamento de peças tipo "supermercado". A montagem final refere-se ao processo de diferenciação dos produtos, possibilitando a flexibilidade e o aumento na variedade do mix de produção, na qual são utilizados, além dos conceitos já citados da montagem bruta, os conceitos de pré-montagem ao lado da linha, o que inclui o fornecimento de subsistemas.

A estruturação das linhas de montagem, da forma descrita, indica uma grande dificuldade de compatibilização do conceito de módulo na produção com a engenharia de produto. A necessidade de fornecer componentes prontos no sistema de supermercado dificulta a adoção do conceito de módulo por função, pois as peças são fornecidas de acordo com a lógica de montagem (e não pela lógica funcional). A empresa adota, na verdade, três conceitos de modularidade que estão presentes na estrutura das duas linhas de montagem citadas anteriormente. Estes conceitos foram identificados na análise documental de procedimentos de produção e confirmados nas entrevistas, a saber:

1."Módulo": o conjunto de apoio montado e fornecido como um único elemento sem que seja especificada uma função no veículo;

2."Sistema": o conjunto de peças e/ou subconjuntos fornecidos já montados na linha de montagem. No entanto, diferentemente do conceito de módulo, os sistemas devem possuir uma função pré-definida no veículo;

3."Kit": o conjunto de peças fornecido desmontado ou parcialmente montado, com ou sem elementos de fixação, podendo ser montado diretamente na linha final ou pré-montado.

Convém destacar que estas definições de módulo, sistema e kit consideradas nas linhas de montagem são anteriores (em termos de quando foram definidas) a adoção do conceito modular (pelo produto), o que sugere que não guardam relação entre si. Os gestores da produção consideram ainda as seguintes definições: produto modular, montagem modular e módulo modular. Nessa óptica, um veículo é um "produto modular" quando, no seu projeto, os sistemas ou subsistemas são agrupados por módulos, os quais são estanques e possuem interdependência apenas no processo de montagem final. 
Ainda, segundo a área de produção, entende-se que a montagem modular, também denominada como modularidade para a produção, implica que a montagem na linha principal seja executada a partir de um módulo ou estrutura básica (esqueleto ou quadro) no qual se fixam os novos módulos com total independência de montagem entre si. Além disso, o conceito de montagem modular representa que todos os módulos são pré-montados fora da linha principal, isto é, antes de atingirem a linha de montagem final do veículo. Neste sentido, pode-se considerar que um veículo possui o conceito modular, no que tange ao modo como a produção o compreende, se e somente se para a produção o veículo permite a adoção desse conceito de montagem modular. Nota-se ainda que este conceito é estritamente ligado à proximidade física dos módulos, dado que sua definição depende da pré-montagem, desconsiderando as semelhanças funcionais entre os componentes do módulo, como prescrito no projeto de desenvolvimento do produto.

Para concluir as definições referentes à aplicação do conceito modular no processo de produção, destaca-se que o conceito de módulo modular é a extensão do conceito de produto modular sendo aplicado ao módulo, por meio da sua subdivisão em submódulos estanques, padronizados e com interdependência apenas de montagem final do módulo, ou seja, nas linhas de pré-montagem. Em resumo, na visão da área de produção, a grande diferença entre o conceito tradicional e o conceito modular reside nas questões de interdependências entre os componentes no processo de montagem final. A Figura 2 ilustra a situação ideal da adoção do conceito modular no que se refere ao processo de produção. Os diversos módulos, que seriam pré-montados, são representados por M1, M2, até MX e MY e são montados em um módulo base.

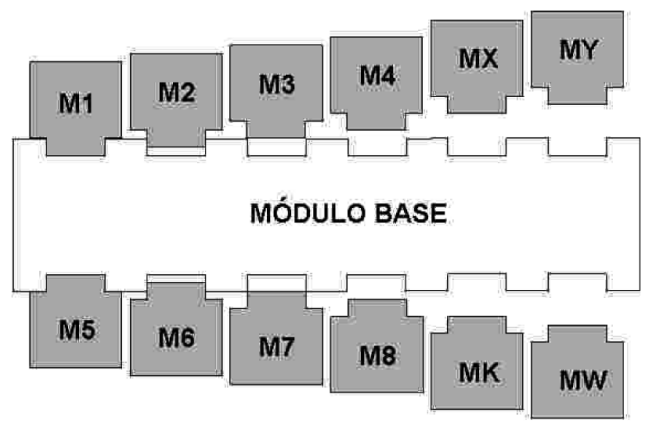

Figura 2 - Montagem do produto no conceito modular (adaptado de documentação da empresa).

A Figura 3 ilustra a possibilidade de adoção de linhas compactas e mais flexíveis, em função da execução de operações em paralelo, comparando as linhas de montagem tradicional serial (Figura 3a) e no conceito modular com pré-montagens (Figura $3 b$ ). O foco de controle da qualidade e do retrabalho passa para o módulo (por meio da realização de poka yoke), transferindo responsabilidades aos fornecedores internos e externos, como é ilustrado na Figura 3b.
(a)Linha de montagem tradicional

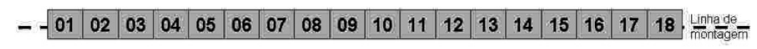

(b) Linha de montagem no conceito modular e pontos de controle da qualidade
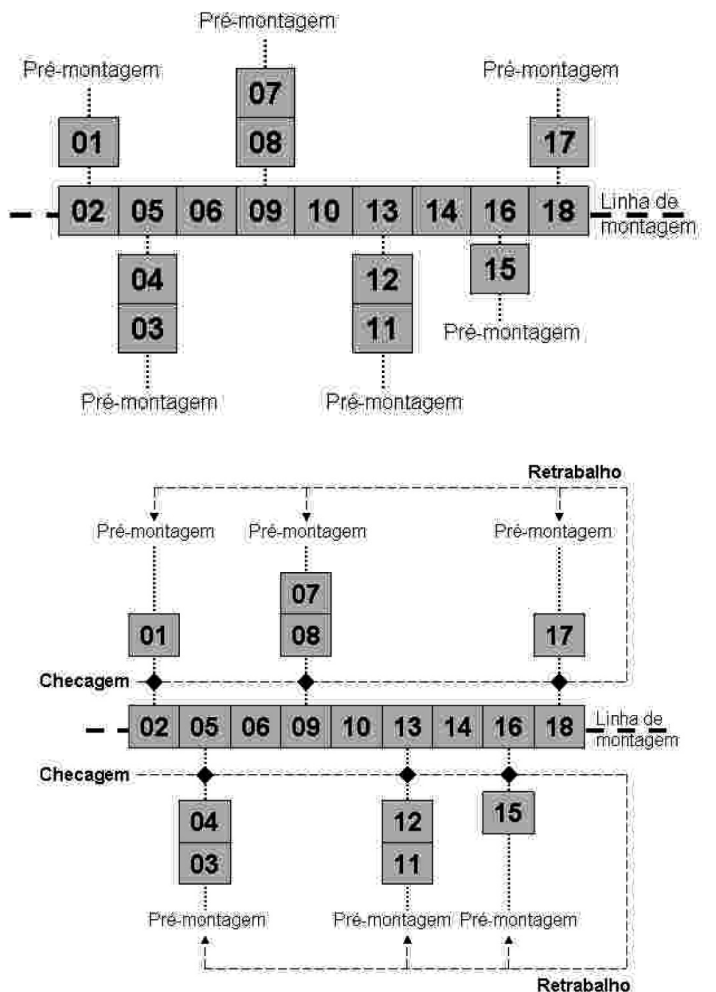

Figura 3 - Linhas de montagem (adaptado da documentação da empresa) - continuação.

Em síntese, o que se pode constatar com os dados coletados é que o significado da modularidade está associado à visão de cada área funcional, seja ela responsável pelo desenvolvimento do projeto do produto ou pela sua fabricação. Isso significa que os conceitos sobre a modularidade adotados são divergentes, principalmente no que se refere à constituição de um módulo. Na visão da engenharia de produto, a divisão dos módulos foi feita de modo conveniente para separar as partes do chassis (Figura 1), apesar de considerar alguns aspectos funcionais. A visão da produção é, no entanto, mais ampla, pois considera uma classificação, relacionada à modularidade, ao considerar módulo, sistema e kit e também as categorizações de produto modular, montagem modular e módulo modular.

\subsection{Discussão dos resultados}

Primeiramente, cabe destacar que os benefícios da modularidade apontados pela empresa estão associados à literatura vigente: redução da complexidade do produto (VELOSO; FIXSON, 2001), diminuição de recursos para desenvolvimento (DORAN et al., 2007; ARNHEITER; HARREN, 2005), aumento da variedade de produtos (ORSATO; WELLS, 2007) e da flexibilidade da produção 
(LAU et al., 2007). Esta é uma constatação importante, pois indica um alinhamento das decisões tomadas, relativas à modularidade, com às fontes bibliográficas consultadas.

Por outro lado, a nomenclatura e definição de sistema, adotada pela empresa, mistura o conceito de módulo com sistema, pois o conceito de sistema considera uma função pré-definida no veículo. A definição de sistema geralmente leva em conta um conjunto de componentes agregados com uma finalidade (que até pode ser funcional). Porém, em uma arquitetura integrada geralmente existe mais de uma função associada ao conjunto, enquanto que em uma arquitetura modular a associação da função com o módulo (e respectivos componentes) é mais direta, como estabelecido por Ulrich e Eppinger (1995).

Observa-se ainda que a noção de módulo, sistema e kit pode ser aplicada ao que se entende conceito modular. Contudo, definidos da forma como o são na produção, não podem ser considerados como parte integrante do conceito modular quando comparados com a literatura (BALDWIN; CLARK, 1997; 2004). Assim, a produção define ainda os termos produto modular, montagem modular, e módulo modular para considerar a modularidade no cotidiano da produção. Porém, não foram encontrados precedentes destes conceitos na literatura vigente.

Finalmente, observa-se então uma visão diferenciada dos conceitos de modularidade nas perspectivas do projeto do produto e da produção. Embora esta diferenciação, aparentemente, não traga divergências ou conflitos entre as áreas (pelo menos não foi identificada esta ocorrência nas entrevistas), muito provavelmente a visão diferente da modularidade pelas áreas funcionais restringem os benefícios da adoção da modularidade no projeto de produto. Assim, restringe-se a transferência do projeto modular para a lógica de como a produção é organizada. No entanto, esta relação de causa-efeito ainda não pode ser confirmada e, por esta razão, um aprofundamento futuro da investigação é necessário, sendo previsto como continuidade da presente investigação.

\section{Conclusões}

Com a condução do estudo de caso, foi possível identificar dois tipos de aplicação da modularidade, advindos da literatura: de projeto e de produção (ou de processo), contribuindo para o objetivo geral da investigação (de analisar a adoção do projeto modular e da modularidade na produção em uma montadora de veículos). Avaliando o projeto modular no desenvolvimento de novos produtos, concluí-se que a engenharia de produto considera que a arquitetura do módulo é definida pela similaridade funcional entre os componentes, isto é, a divisão do produto complexo proposta segue a finalidade de cada um dos módulos que serão utilizados. Em contrapartida, a produção considera como módulo todo conjunto de apoio que é fornecido já pronto à linha de montagem, ou seja, a lógica da arquitetura do módulo é baseada na relação física entre as partes. Neste sentido, nota-se que a adoção do conceito de modularidade no objeto de estudo apresenta uma divergência em relação à visão do significado da modularidade no projeto e de produção, pela avaliação da compreensão do conceito de modularidade por estas áreas (produto e produção).

Observou-se também algumas das práticas adotadas pela empresa, podendo-se concluir que estas são disseminadas mas distintas entre as áreas, corroborando a lógica anteriormente apontada da visão diferenciada da modularidade entre as áreas funcionais. No entanto, uma limitação na presente investigação refere-se à verificação da relação entre o desenvolvimento de novos produtos modulares e a modularidade na produção, no sentido de uma relação de causa e efeito. Esta relação será investigada na continuidade do presente trabalho.

Um outro aspecto que emergiu da investigação na empresa refere-se à atuação dos fornecedores, seja no projeto ou na produção dos módulos. Embora este não tenha sido o foco principal desta investigação, é um tema importante para a continuidade da presente investigação. Apesar de a literatura apontar que questões de outsourcing são muito facilitadas pela adoção do conceito modular, no caso da empresa em questão (que prioriza a verticalização da produção), praticamente não existe o outsourcing. No entanto, um raciocínio análogo pode ser aplicado ao conceito de fornecedores internos. Outro aspecto marginalmente investigado, mas importante, é a constatação de que o investimento necessário à adaptação da linha de produção para um conceito "puramente modular", a partir do projeto, seriam possivelmente inviável. O investimento seria significativo, sendo que o prazo de retorno (definido pela empresa) não o viabilizaria.

Finalmente, avaliando o caso apresentado, o que se percebe é que a empresa investigada desenvolve seus conceitos internos sobre a modularidade, o que pôde ser evidenciado nos documentos disponibilizados pelas áreas. Nesse sentido, também como continuidade do presente estudo, pretende-se investigar em maior profundidade outras decorrências da adoção da modularidade (gestão da qualidade e dos fornecedores, relações na cadeia de suprimentos etc.), principalmente tendo o projeto modular como referência. Pretende-se também ampliar o trabalho de campo, considerando mais casos, a fim de aumentar o grau de generalização da investigação, que hoje em dia é limitado a um único caso.

\section{Agradecimentos}

Os autores agradecem o apoio da FAPESP (processo 2007/ 02877-6), CNPq (PQ 304588/2007-5 e bolsas de iniciação 
científica), e a empresa que permitiu a realização da investigação

\section{Referências}

ALLER, R.A. New tendencies in inter-firm relations in the automotive industry and their impact on European periphery suppliers: Lessons from Spain. European Urban and Regional Studies, v.6, n.3, 1999.

ANDO, R. A modularidade e seus impactos no desenvolvimento de novos produtos e processos na indústria automotiva. Dissertação de Mestrado, FEA USP, Departamento de Adiministração. São Paulo, 2004.

ARBIX, G.; ZILBOVICIUS, M. Consórcio modular da $V W$ : um novo modelo de produção? In: ARBIX, G.; M. ZILBOVICIUS, De JK a FHC: a reinvenção dos carros. São Paulo: Scritta, 1997.

ARNHEITER, E.D.; HARREN, H. A typology to unleash the potential of modularity. Journal of Manufacturing Technology Management, v. 16, n. 7, 699-711, 2005.

BALDWIN, C.Y.; CLARK, K.B. Modularity in the design of complex engineering systems. 2004. Disponível em: $<$ http://www.people.hbs.edu/cbaldwin/DR2/BaldwinClark CES.pdf01.> Acesso em: 20 de jul. 2007.

BALDWIN, C. Y.; CLARK, K.B. Design rules. Massachusetts: MIT Press, 2000.

BALDWIN, C. Y.; CLARK, K.B. Managing in the age of modularity. Harvard Business Review. 1997.

CAMUFFO, A. Rolling out a world car: globalization, outsourcing and modularity in the auto industry. 2000. Disponível: IMVP Working paper: <http://imvp.mit. edu.papers.> Acesso em: 15 de out. 2006.

DIAS, A.V. Consórcio modular e condomínio industrial: elementos para a análise de novas configurações produtivas na indústria automobilística. EPUSP, São Paulo, 1998.

DORAN, D; HILL, A; HWANG, K.S.; JACOB, G. Supply chain modularization: Cases from the French automobile industry. International Journal of Production Economics, v. 106, n. 1, p. 2-11, 2007.

FILIPPINI, R. Operations Management Research: Some Reflections on Evolution, Models and Empirical Studies in OM. International Journal of Operations and Production Management, v. 17, n. 7, p. 655-670, 1997.
FRESSENET, M.; LUNG, Y. Between globalization and regionalization: what is the future of the automobile industry. In: J. HUMPHREY, Y.LACLER, e M. SALERNO, Global strategies and local realities: the auto industry in emerging markets. New York: Macmillan Press, p. 7294, 2000.

GRAZIADIO, T. Estudo comparativo entre os fornecedores de componentes automotivos de plantas convencionais e modulares. Tese de Doutorado. São Paulo: EPUSP, 2004.

HAMPHREY, J; LECLER, Y.; SALERNO, M. Global strategies and local realities: the auto industry in emerging markets. New York: Macmillan, 2000.

HELPER, S; MACDUFFIE, J. P.; PIL, F. Modularization and outsourcing: implications for the future of automotive assembly. International Vehicle Program (IMVP), 1999.

LAU, A.K.W; YAM, R.C.M.; TANG, E. The impacts of product modularity on competitive capabilities and performance: An empirical study. International Journal of Production Economics, v. 105, n. 1, p. 1-20, 2007.

LEE, W.B. et al. A fuzzy analytic hierarchy process approach in modular product design. Expert Systems, v. 18, n. 1, p. 32-42, 2001.

MIGUEL, P. Estudo de caso na engenharia de produção: estruturação e recomendações para sua condução. Produção, v. 17, n. 1, p. 216-229, 2007.

MILLES, M.B. e HUBERMAN, A.M. Qualitative Data Analysis - An Expanded Sourcebook. Thousand Oaks: Sage Publications, 1994.

MOAVENI, S. Finite Element Analysis - Theory and Application with ANSYS. New Jersey: Prentice Hall, 2000.

O'GRADY, S. The age of modularity. London: Adams and Steele Publishers, 1999.

ORSATO, R.J.; WELLS, P. U. Turn: the rise and demise of the automobile industry. Journal of Cleaner Production, v. 15, n. 11-12, p. 994-1006, 2007.

PANDREMENOS, J. et al. Modularity concepts for the automotive industry: a critical review. CIRP Journal of Manufacturing Science and Technology, v. 1, p. 148152, 2009. 
RAMALHO, J; SANTANA, M. A indústria automobilística no Rio de Janeiro: relações de trabalho em um contexto de desenvolvimento regional. In: M. NABUCO, M. NEVES; A. NETO, Indústria automotiva: a nova geografia do setor produtivo. Rio de Janeiro: DP\&A, 2002.

SALERNO, M; MARX, R.; ZILBOVICIUS, M. A nova configuração da cadeia automotiva brasileira. Relatório de Pesquisa, EPUSP, Departamento de Engenharia de Produção, São Paulo, 2002.

SALERNO, M; ZILBOVICIUS, M.; ARBIX, G. Mudanças e persistências no padrão de relações entre montadoras e autopeças no Brasil. Revista de Administração FEAUSP, v. 33, jul.-set; p. 16-28, 1998.

STARR, M. K. Modular production: a new concept. Harvard Business Review, v. 43, n. 6, p. 131-142, 1965.

ULRICH, K.; EPPINGER, S. Product design and development. New York: McGraw-Hill, 1995.
VAN HOEK, R. I., e WEKWN, H. A. The impact of modular production on the dynamics of supply chains. The International Journal of Logistics Management, v. 9, n. 2, p. 35-50, 1998.

VELOSO, F.;FIXSON, S. Make-Buy decisions in the auto industry: new perspectives on the role of the supplier as an innovator. Technological Forecasting \& Social Change, v. 67, n. 2-3, p. 239-257, 2001.

VOSS, C. E. Case Research in Operations Management. International Journal of Operations and Production Management, v. 22, n. 2, p. 195-219, 2002.

YIGIT, A. et al. Optimizing modular product design for reconfigurable manufacturing. Journal of Intelligent Manufacturing, v. 13, n. 4, p. 309-316, 2002. 